\title{
Caspase recruitment domain (CARD) family (CARD9, CARD10, CARD11, CARD14 and CARD15) are increased during active inflammation in patients with inflammatory bowel disease
}

Jesús K. Yamamoto-Furusho ${ }^{1 *}$ (D), Gabriela Fonseca-Camarillo ${ }^{1+}$, Janette Furuzawa-Carballeda ${ }^{2 \dagger}$, Andrea Sarmiento-Aguilar ${ }^{1}$, Rafael Barreto-Zuñiga ${ }^{3}$, Braulio Martínez-Benitez ${ }^{4}$ and Montserrat A. Lara-Velazquez ${ }^{5}$

\begin{abstract}
Background: The CARD family plays an important role in innate immune response by the activation of NF-KB. The aim of this study was to determine the gene expression and to enumerate the protein-expressing cells of some members of the CARD family (CARD9, CARD10, CARD11, CARD14 and CARD15) in patients with IBD and normal controls without colonic inflammation.

Methods: We included 48 UC patients, 10 Crohn's disease (CD) patients and 18 non-inflamed controls. Gene expression was performed by RT-PCR and protein expression by immunohistochemistry. CARD-expressing cells were assessed by estimating the positively staining cells and reported as the percentage.

Results: The CARD9 and CARD10 gene expression was significantly higher in UC groups compared with CD $(P<0.001)$. CARD11 had lower gene expression in UC than in CD patients $(P<0.001)$. CARD14 gene expression was higher in the group with active UC compared to non-inflamed controls $(P<0.001)$. The low expression of CARD14 gene was associated with a benign clinical course of UC, characterized by initial activity followed by long-term remission longer than 5 years $(P=0.01, \mathrm{OR}=0.07,95 \% \mathrm{Cl}: 0.007-0.70)$. CARD15 gene expression was lower in UC patients versus $C D(P=0.004)$. CARD9 protein expression was detected in inflammatory infiltrates; CARD14 in parenchymal cells, while CARD15 in inflammatory and parenchymal cells. CARD9-, CARD14- and CARD15 - expressing cells were significantly higher in patients with active UC versus non-inflamed controls $(P<0.05)$.
\end{abstract}

Conclusion: The CARD family is involved in the inflammatory process and might be involved in the IBD pathophysiology.

Keywords: Innate, Receptors, CARD, Ulcerative colitis, Gene, PCR

\footnotetext{
* Correspondence: kazuofurusho@hotmail.com

${ }^{\dagger}$ Gabriela Fonseca-Camarillo and Janette Furuzawa-Carballeda contributed equally to this work.

'Department of Gastroenterology, Inflammatory Bowel Disease Clinic, Instituto Nacional de Ciencias Médicas y Nutrición Salvador Zubirán, Vasco de Quiroga 15, Colonia Sección XVI, Tlalpan, CP, 14000 Mexico City, Mexico Full list of author information is available at the end of the article
}

C) The Author (s). 2018 Open Access This article is distributed under the terms of the Creative Commons Attribution 4.0 International License (http://creativecommons.org/licenses/by/4.0/), which permits unrestricted use, distribution, and reproduction in any medium, provided you give appropriate credit to the original author(s) and the source, provide a link to the Creative Commons license, and indicate if changes were made. The Creative Commons Public Domain Dedication waiver (http://creativecommons.org/publicdomain/zero/1.0/) applies to the data made available in this article, unless otherwise stated. 


\section{Background}

Ulcerative Colitis (UC) is one of the two forms of Inflammatory Bowel Disease (IBD). Epidemiologic data from developing countries reveals that the incidence and prevalence of IBD are increasing in different regions around the world [1]. Family-based studies have identified a number of familial IBD loci using nonparametric linkage analyses, where IBD1 locus contains NOD2 gene $[2,3]$. The NOD2 or CARD15, the first gene associated to Crohn's disease (CD), is an intracellular receptor of the Nod Like Receptor (NLR) family that binds to muramyldipeptide (MDP), the minimal bioactive component of bacterial peptidoglycan [4], and through Nuclear Factor $\kappa \mathrm{B}(\mathrm{NF}-\mathrm{\kappa} \mathrm{B})$ pathway, it regulates the expression of tumor necrosis factor (TNF) and other pro-inflammatory cytokines [5].

The CARD-containing adaptors and sensors represent an important family of 15 molecules involved in innate host defense against gastrointestinal pathogens and in the regulation of inflammatory responses. CARD15 has been found to be a key orchestrator of the intestinal mucosal barrier homeostasis through the regulation of intestinal microbiota as well as innate and adaptive immune responses [6-8]. It belongs to CARD family, which also includes CARD9, CARD10, CARD11 and CARD14, among others.

The CARD9 is an adaptor molecule found mainly in lymphoid tissues, it plays a role in the innate immune response to fungi, bacteria, virus and mycobacteria, linking innate immunity with T-cell differentiation and type $17 \mathrm{~T}$ helper (Th17)-cell development [9-12]; it is known that the presence of certain genetic variants of CARD9 implies an increased risk of IBD [13]. It participates in the activation of NF- $\kappa \mathrm{B}$ under dectin-1 (C-type lectin domain family 7-member $\mathrm{A}, C L E C 7 A$ ) stimulation and interactions between commensal fungi and the c-type lectin receptor dectin-1 influence colitis [11], which haplotype rs2078178-rs16910631 was found to be associated with CD and UC [13]. It physically associates with CARD15 in response to MDP and regulates the activation of the kinases p38 and JNK, required for the expression of inflammatory cytokines [12-14]. With the appearance of double-stranded DNA (dsDNA) in the cytoplasm, it forms part of the signaling complex dsDNA-Rad50-CARD9 and culminates with activation of the transcription factor NF-kB and the generation of pro-IL-1 $\beta$ [15]. CARD10, CARD11 and CARD14 are members of the membraneassociated guanylate kinase (MAGUK) superfamily, and function as molecular scaffolds by using multiple discreet protein interaction domains to cluster receptors and cytosolic signaling molecules at the cell membrane [13-15]. They contain three defining interaction domains: the PSD-95/Dlg/Z0-1 homologous (PDZ) domain, the Src- homology (SH3) domain and the guanylate kinase
(GUK)-like domain. Their CARD domain, interacts specifically with the CARD of BCL-10, and under different stimuli, they activate NF- $\mathrm{B}$ [16]. These three molecules have shown distinct tissue distributions but share $50-60 \%$ sequence identity in the CARD and coiled-coil domains, and $20-30 \%$ identity in the PDZ, SH3 and GUK domains [17-19]. CARD10 is expressed in a variety of adult tissues like heart, kidney, liver and multiple cancer cell lines including colorectal adenocarcinoma SW480 cells [20]. It interacts with Bcl10 and MALT1 in the platelet-activating factor (PAF)-induced inflammatory pathway in intestinal epithelial cells, and the pro-inflammatory effects of PAF play prominent roles in the pathogenesis of IBD [21]. CARD11 is expressed in the spleen, thymus and peripheral blood leukocytes, it is an important component of the antigen-induced NF-kB signaling pathway in T cells [16], and interestingly, certain genetic variants were associated with an incremented risk of UC [3]. CARD14 gene expression has been found in placenta, skin and mucosa, and it is the only member of the family so far shown to be expressed in different alternatively spliced isoforms [22-25]; its role in the context of IBD is unknown. The aim of this study was to determine the gene expression and to enumerate the protein-expressing cells of some members of the CARD family (CARD9, CARD10, CARD11, CARD14 and CARD15) in patients with IBD and normal controls without colonic inflammation.

\section{Methods}

\section{Study subjects}

A total of 48 patients with UC (26 patients with active $\mathrm{UC}$ and 22 patients with UC in remission), 10 patients with ileocolonic CD (1 patient with active $\mathrm{CD}$ and 9 patients with $\mathrm{CD}$ in remission) and 18 controls without colonic inflammation were included in the study. All colonic biopsies from patients with IBD and controls were taken from colon mucosa inflamed whole colon in UC and right colon in CD patients.

The diagnosis of UC was performed by the presence of the following criteria: presence of chronic diarrhea with blood in stools, macroscopic endoscopic appearance and confirmation by histopathology.

All IBD patients were included during the period from January 2014 to July 2015, belonging to the Inflammatory Bowel Disease Clinic at the National Institute of Medical Sciences and Nutrition "Salvador Zubirán". Relevant clinical and demographic information from all patients were collected from interview and medical records (Table 1). Variables analyzed were age at diagnosis, gender, type of medical treatment (5-aminosalycilates, steroids, thiopurines, biologic therapy), disease extension or location according to Montreal Classification, the presence of extra-intestinal manifestations such as articular affection, ankylosing spondylitis, sacroiliitis, sclerosing cholangitis, 
Table 1 Demographic, clinical and laboratory variables of patients with UC and controls

\begin{tabular}{|c|c|c|c|c|}
\hline VARIABLES & ACTIVE UC $(n=26)$ & REMISSION UC $(n=22)$ & CROHN'S DISEASE $(n=10)$ & CONTROL GROUP $(n=18)$ \\
\hline \multicolumn{5}{|l|}{$\overline{\text { Age }}$} \\
\hline Mean \pm SD (years) & $37.7 \pm 10.5$ & $39.0 \pm 13.7$ & $45.2 \pm 19.7$ & $47.7 \pm 11.4$ \\
\hline Median & 38 & 35 & 41 & 52 \\
\hline Range & $20-57$ & $20-66$ & $21-85$ & $24-60$ \\
\hline \multicolumn{5}{|l|}{ Gender } \\
\hline Female (\%) & $13(50)$ & $12(55)$ & $2(20)$ & $11(61)$ \\
\hline Male (\%) & $13(50)$ & $10(45)$ & $8(80)$ & $7(39)$ \\
\hline \multicolumn{5}{|l|}{ Clinical course } \\
\hline Relapsing-remitting (\%) & 80.7 & 22.7 & 0 & NA \\
\hline Remission (\%) & 15.3 & 77.2 & 87.5 & NA \\
\hline Continuous activity (\%) & 3.8 & 0 & 12.5 & NA \\
\hline Extra intestinal manifestations (\%) & 64 & 27.2 & 33 & NA \\
\hline \multicolumn{5}{|l|}{ Disease duration } \\
\hline Mean \pm SD (years) & $6.03 \pm 4.96$ & $11.59 \pm 6.7$ & $7.2 \pm 8.8$ & NA \\
\hline Median & 4.5 & 11.5 & 5.5 & NA \\
\hline Range & 0-19 & $1-30$ & $0-27$ & NA \\
\hline \multicolumn{5}{|l|}{ Treatment } \\
\hline 5-aminosalycilates (\%) & 38.5 & 54.5 & 50.0 & NA \\
\hline 5-aminosalycilates + steroids (\%) & 61.5 & 45.5 & 50.0 & NA \\
\hline Steroid dependent (\%) & 3.8 & 0.0 & 12.5 & NA \\
\hline Steroid resistant (\%) & 23.0 & 18.2 & 12.5 & NA \\
\hline \multicolumn{5}{|l|}{ Histopathology severity } \\
\hline Inactive disease (\%) & 0 & 100 & 11 & NA \\
\hline Mild (\%) & 28 & 0 & 89 & NA \\
\hline Moderate (\%) & 24 & 0 & 0 & NA \\
\hline Severe (\%) & 48 & 0 & 0 & NA \\
\hline Dysplasia (\%) & 0 & 0 & 0 & NA \\
\hline \multicolumn{5}{|l|}{ Laboratory values } \\
\hline Hemoglobin $(\mathrm{g} / \mathrm{dL}$ ), Mean \pm SD & $12.9 \pm 2.9^{*}$ & $14.3 \pm 1.4$ & $13.9 \pm 2.1$ & $14.8 \pm 1.8$ \\
\hline Median & 13.6 & 14.6 & 14.4 & 14.9 \\
\hline Range & $5.6-18.3$ & $10.7-16.4$ & $8.9-16.5$ & $10.6-17.6$ \\
\hline Mean corpuscular volume (fL), Mean \pm SD & $83.4 \pm 8.1$ & $88.5 \pm 5.0$ & $89.2 \pm 7.3$ & $90.2 \pm 5.3$ \\
\hline Median & 85.2 & 89.0 & 91.4 & 91.1 \\
\hline Range & $62.3-93.9$ & $79.5-98.1$ & 72.0-96.3 & $73.5-95.7$ \\
\hline \multicolumn{5}{|l|}{ Mean corpuscular hemoglobin (pg/cell), } \\
\hline Mean \pm SD & $27.5 \pm 3.3$ & $30.0 \pm 2.2$ & $30.2 \pm 2.6$ & $30.7 \pm 2.2$ \\
\hline Median & 28.5 & 30.4 & 30.4 & 31.2 \\
\hline Range & $20.2-31.8$ & $25.8-33.8$ & $24.0-32.9$ & $23.6-33.2$ \\
\hline Leukocytes $\left(10^{3} / \mu \mathrm{L}\right)$, Mean \pm SD & $8.3 \pm 2.5$ & $6.8 \pm 2.7$ & $6.6 \pm 3.1$ & $7.0 \pm 2.3$ \\
\hline Median & 8.6 & 6.2 & 5.5 & 6.6 \\
\hline Range & $3.7-13.9$ & $4.6-17.4$ & $4.2-14.7$ & $3.4-13.1$ \\
\hline Neutrophils (\%), Mean \pm SD & $62.5 \pm 12.2$ & $63.2 \pm 8.5$ & $70.5 \pm 10.4$ & $58.0 \pm 9.7$ \\
\hline Median & 63.2 & 61.6 & 70.3 & 59.8 \\
\hline Range & $35.0-85.0$ & $46.6-81.2$ & $53.4-91.0$ & $39.4-75.6$ \\
\hline
\end{tabular}


Table 1 Demographic, clinical and laboratory variables of patients with UC and controls (Continued)

\begin{tabular}{|c|c|c|c|c|}
\hline VARIABLES & ACTIVE UC $(n=26)$ & REMISSION UC $(n=22)$ & CROHN'S DISEASE $(n=10)$ & CONTROL GROUP $(n=18)$ \\
\hline Lymphocytes (\%), Mean \pm SD & $26.5 \pm 9.9$ & $27.4 \pm 8.3$ & $20.5 \pm 8.9$ & $30.6 \pm 9.4$ \\
\hline Median & 26.4 & 27.6 & 18.3 & 27.5 \\
\hline Range & $10.0-44.0$ & $14.8-44.5$ & $6.6-35.4$ & $15.2-50.5$ \\
\hline Monocytes (\%), Mean \pm SD Median & $7.9 \pm 2.6$ & $7.1 \pm 2.2$ & $7.9 \pm 3.5$ & $7.4 \pm 1.8$ \\
\hline Median & 7.8 & 6.8 & 7.5 & 7.3 \\
\hline Range & $3.9-12.8$ & $2.5-11.1$ & $1.8-14.5$ & $3.7-11.0$ \\
\hline Platelets units $\left.10^{3} / \mu \mathrm{L}\right)$, Mean \pm SD & $375.3 \pm 142.0$ & $238.0 \pm 89.7$ & $183.4 \pm 58.1$ & $212.2 \pm 70.0$ \\
\hline Median & 371.0 & 229.0 & 187.0 & 207.0 \\
\hline Range & $155.0-869.0$ & $68.0-436.0$ & $94.0-227.0$ & $105.0-325.0$ \\
\hline \multicolumn{5}{|l|}{ Erythrocyte Sedimentation Rate $(\mathrm{mm} / \mathrm{h})$, } \\
\hline Mean \pm SD & $23.6 \pm 18.8$ & $13.1 \pm 12.0$ & $8.0 \pm 6.9$ & $3.5 \pm 1.9$ \\
\hline Median & 17.5 & 11.0 & 4.0 & 3.0 \\
\hline Range & $2.0-66.0$ & $2.0-46.0$ & $2.0-19.0$ & $2.0-6.0$ \\
\hline \multicolumn{5}{|l|}{ Environmental exposure } \\
\hline Tobacco (\%) & 54.0 & 72.3 & 44.4 & 22.2 \\
\hline Alcohol (\%) & 35.0 & 31.8 & 22.2 & 16.6 \\
\hline \multicolumn{5}{|l|}{ Comorbidities } \\
\hline Allergies (\%) & 3.8 & 9 & 0 & 16.6 \\
\hline Autoimmune diseases (\%) & 3.8 & 13.6 & 11.1 & 16.6 \\
\hline \multicolumn{5}{|l|}{ Medical history } \\
\hline Hypertension (\%) & 0 & 4.5 & 0 & 22.2 \\
\hline Overweight/obesity (\%) & 0 & 0 & 0 & 5.5 \\
\hline Diabetes (\%) & 0 & 0 & 11.1 & 11.1 \\
\hline Dyslipidemia (\%) & 0 & 4.5 & 0 & 22.2 \\
\hline Gynecologic diseases (\%) & 3.8 & 18.1 & 0 & 16.6 \\
\hline Surgery history (\%) & 61.5 & 68.1 & 55.5 & 55.5 \\
\hline
\end{tabular}

CD crohn's disease, UC ulcerative colitis

Hemoglobin $p=0.018$ (active ulcerative colitis vs. control group)

Mean corpuscular volume $p=0.008$ (active ulcerative colitis vs. control group) and $p=0.048$ (remission ulcerative colitis vs. control group) Neutrophils $p<0.001$

(Crohn's disease vs. control group)

Erythrocyte sedimentation rate $p=0.042$ (active ulcerative colitis vs. control group) and $p=0.0498$ (active ulcerative colitis vs. Crohn's disease)

Non-parametrical tests were used such as U Mann Whitney test for numerical variables and Fisher Exact test for categorical variables

pyoderma gangrenosum, erythema nodosum or uveitis and clinical course classified as: initially active and then prolonged remission (first episode with activity and then long-term remission for more than 5 years), intermittent activity ( $>2$ relapses per year) and chronic continual activity (persistent activity despite medical conventional therapy).

Colonoscopy was performed to calculate the Mayo Score Activity Index and Riley for endoscopy and histology activity, respectively [26-28]. The disease severity was evaluated by Harvey-Bradshaw Index for CD patients [29].

In IBD patients, the colonic biopsies were taken from the whole colon in $\mathrm{UC}$ patients and right colon in CD patients, especially in the most severe inflammation evaluated by colonoscopy.
The histological analysis of those patients with active UC showed that $28 \%$ of the patients had mild activity, $24 \%$ moderate and $48 \%$ with severe histological inflammation. The remaining $22 \mathrm{UC}$ patients in remission were confirmed by histopathology. Regarding to the treatment, all patients were taking sulfasalazine or 5-aminosalicylic acid (5-ASA); $47.5 \%$ used systemic steroids; $30 \%$ were taking thiopurines and $2.5 \%$ received anti-TNF therapy.

The control group consisted of non-inflamed controls (no documented inflammatory disease) undergoing to colonoscopy for other reasons and approving by written informed consent the use of specific colonic biopsies for this study.

\section{Sample processing and gene expression analysis}

All colonic biopsies were taken by colonoscopy and were immediately placed in RNA later (Ambion, Austin, TX, 
USA) and stored at $-70{ }^{\circ} \mathrm{C}$ until processing. Then total RNA was isolated using High Pure RNA Tissue (Roche Diagnostics, Mannheim, Germany), following the manufacturer's guidelines. Two hundred nanograms of total RNA were reverse-transcribed into cDNA with random hexamer primers (Roche Diagnostics, Mannheim, Germany).

The PCR amplification of the above mentioned genes was carried out with $20 \mathrm{ng}$ of cDNA, $200 \mathrm{nM}$ forward and reverse primer, and Taqman Master Mix (Roche Diagnostics, Mannheim, Germany Roche Diagnostics, Mannheim, Germany) in a final volume of $10 \mu \mathrm{l}$. PCR reactions were run in a Light Cycler 2.0 (Roche Diagnostics, Mannheim, Germany) for 45 cycles, each cycle consist in denaturation for $15 \mathrm{~s}$ at $95^{\circ}$, primer annealing for $15 \mathrm{~s}$ at $55^{\circ}$, and extension for $30 \mathrm{~s}$ at $72{ }^{\circ} \mathrm{C}$ and cooling $30 \mathrm{~s}$ at $40{ }^{\circ} \mathrm{C}$.

The CARD gene expression was measured by real-time polymerase chain reaction (RT-PCR). Reference gene GADPH transcripts were used for relative quantification and quality controls. For q-PCR assays quality control, determination of linearity and reproducibility was evaluated ( $\mathrm{VC}<10 \%)$. The mRNA relative quantification of target genes was conducted using the LightCycler software 4.1, according to the 2-delta-delta Ct method. Table 2 shows the details of the primers designs used for the RT-PCR.

\section{Double staining immunohistochemistry procedure}

A total of 10 surgical specimens from patients with active severe UC refractory to conventional therapy were included for ex-vivo protein detection as well as 10 patients with definitive diagnosis of ileocolonic active $\mathrm{CD}$ were enrolled in the study. Ten controls were obtained from noninflamed non-IBD intestinal tissue.

In order to determine the CARD9, CARD14 and CARD15-expressing cells, $4 \mu \mathrm{m}$ thick sections of formalinfixed paraffin embedded tissue were placed on positively charged slides. Sections were deparaffinized with xylene and rehydrated with a graded series of ethanol and water washes before staining.

Follow the standard dewaxing and rehydration, enzyme antigen retrieval was performed (Enzo Life Sciences, Inc., Farmingdale, NY, USA). Tissues were blocked with a peroxidase solution. Then non-specific background staining was avoided with the IHC background blocker (Enzo Life Sciences). To determine the subpopulation of CARD15 +/CD14+ and CARD9+/CARD14 cells a simultaneous detection was performed (MultiView (mouse-HRP/rabbit-AP) Enzo Life Sciences). The procedure is a sequential double staining where the IHC universal negative control reagent, as negative control (Enzo Life Sciences) and the mouse monoclonal anti-CARD9 IgG2a antibody (Santa Cruz Biotechnology, Santa Cruz, CA, USA)/rabbit polyclonal anti-CARD14, and the mouse monoclonal anti-CARD15 IgG1 antibody/rabbit polyclonal anti-CARD14 (Santa Cruz Biotechnology) at $10 \mu \mathrm{g} / \mathrm{mL}$ were incubated during $30 \mathrm{~min}$ at room temperature. Slides were washed and then incubated with PolyView IHC reagent (mouse-HRP) and PolyView IHC reagent (rabbit-AP) for $20 \mathrm{~min}$. Finally, antigens were visualized using horseradish peroxidase (HRP)/3, 3'-diaminobenzidine (DAB) and the second antigen with alkaline phosphatase (AP)/Permanent Red. Tissues were counterstained with Harris' hematoxylin and mounted with permanent mounting medium. $\mathrm{CARD9}^{+}-$, CARD $14^{+}-$and $\mathrm{CARD}^{-} 5^{+}$-expressing cells were assessed by estimating the positively staining cells in three fields $(\times 320)$ and were reported as the percentage of immunoreactive cells of the inflammatory infiltrates located at mucosa, submucosa, muscular and serosa. Results are expressed as the mean \pm standard error of the mean (SEM) of cells quantified by the program Image Pro Plus version 5.1.1.

Table 2 Primers designs used for Real Time Polymerase Chain Reaction (RT-PCR)

\begin{tabular}{|c|c|c|c|c|c|}
\hline GENE & GENEBANK & OLIGO LEFT & OLIGO RIGHT & $\begin{array}{l}\text { UNIVERSAL } \\
\text { PROBE LIBRARY }\end{array}$ & AMPLICON SIZE \\
\hline CARD9 & $\begin{array}{l}\text { NM_052814.3, } \\
\text { NM_052813.4 }\end{array}$ & ggagacgctcgtcctgag & aggtcctgggggagtgag & 79 & $\begin{array}{l}\text { gagacgctcgtcctgagctccgacctggaagatggctcacccagga } \\
\text { ggtcccaggagctctcactcccccaggacct }\end{array}$ \\
\hline CARD10 & NM_014550.3 & actaccccgaacacttcacg & gtcatcaagaattgggtcagg & 72 & $\begin{array}{l}\text { actaccccgaacacttcacgctgctcacgggccaggaacccgcccag } \\
\text { cgctgctccatgatcctcgatgaggaggggectgaggggcctgaccc } \\
\text { aattcttgatgac }\end{array}$ \\
\hline CARD11 & NM_032415.4 & cagaggagctgcgagacaa & ggtgcttgtacatttcacagtcc & 1 & $\begin{array}{l}\text { cagaggagctgcgagacaagtacctggaggagaaggaggacctgg } \\
\text { agctcaagtgctcgaccctgggaaaggactgtgaaatgtacaagcacc }\end{array}$ \\
\hline CARD14 & NM_024110.3 & gagctcctagacacggcaga & cgagacatcaagccttccag & 71 & $\begin{array}{l}\text { gagctcctagacacggcagaccttccgcagctggaaagcagectgca } \\
\text { gccagtctcccctggaaggcttgatgtctc }\end{array}$ \\
\hline CARD15 & NM_022162.1 & gtgtcctcctcggacattct & ggaccctgagaccagcag & 36 & $\begin{array}{l}\text { gtgtcctcctcggacattctccgggttgtgaaatgtgctcgcaggagge } \\
\text { ttttcaggcacagaggagccagctggtcgagctgctggtctcagggtcc }\end{array}$ \\
\hline GAPDH & NM_002046.3 & agccacatcgctcagaca & gcccaatacgaccaaatcc & 60 & $\begin{array}{l}\text { agccacatcgctcagacaccatggggaaggtgaaggtcggagtcaac } \\
\text { ggatttggtcgtattgggc }\end{array}$ \\
\hline
\end{tabular}




\section{Ethical considerations}

This study was performed according to the principles expressed in the Declaration of Helsinki. The study was approved by the Ethical and Research Committee from the Instituto Nacional de Ciencias Médicas y Nutrición, and a written informed consent was obtained in all subjects.

\section{Statistical analysis}

We used descriptive statistical analysis for demographical variables. The Kruskall Wallis is a non-parametric test for analyzing the differences in the gene expression between all groups. For categorical variables was used the Fisher's exact test for non-parametric variables. The Odds Ratio (OR) was used in order to determine association between gene expression and clinical outcomes. Immunohistochemistry analysis was done by using one-way analysis of variance on ranks by Holm-Sidak method and Dunn's test for all pairwise multiple comparison procedures. The Sigma Stat 11.2 program (Aspire Software International, Leesburg, VA, USA) and SPSS version 17.0 statistical program were used for the analysis. A $P$ value below of 0.05 was considered as significant.

\section{Results}

\section{Demographic and clinical characteristics}

All demographic, laboratory, and clinical data from patients and controls are shown in Table 1. Regarding to disease activity, 26 had active disease and 22 were in remission according to Mayo and Riley Scores. The extent of disease was evaluated by using total colonoscopy and biopsies were taken from all segments of colon. The Montreal classification was used to define the extent of UC.

\section{CARD9, CARD10 and CARD11 gene expression in colonic tissue of UC patients}

The CARD9 gene expression was higher in the active UC compared to the group with remission UC $(P=0.05)$ and CD group $(P<0.001)$. The CARD9 and CARD10 gene expression was higher in the remission group compared to inflamed CD $(P<0.001$; Fig. 1a and b) and only CARD9 had lower levels than non-inflamed control group $(P=0.004 ;$ Fig. 1a). No significant associations were found between the CARD9 gene expression and clinical characteristics of IBD.

The CARD11 gene expression was lower in active and remission UC groups compared to $C D$ inflamed group $(P \leq 0.001)$. No statistically significant differences were found in CARD11 gene expression in UC versus noninflamed control group (Fig. 1c).

\section{CARD14 gene expression was associated with a more benign clinical course}

The CARD14 gene expression was higher and statistically significant in the group with active UC compared to inflamed $C D$ and non-inflamed controls $(P<0.001$; Fig. $1 d)$. The low expression of CARD14 gene in remission UC patients was associated with a benign clinical course of the disease, characterized by initial activity followed by long-term remission longer than 5 years $(P=0.01$, $\mathrm{OR}=0.07,95 \% \mathrm{CI}: 0.007-0.70)$.

CARD15 gene expression in colonic tissue of UC patients CARD15 gene expression was significantly higher in patients with $\mathrm{CD}$ compared to active UC $(P=0.004)$. No statistical significant difference was found in the gene expression of CARD15 between UC in remission versus non-inflamed control group (Fig. 1e).

Finally, no significant associations were found between CARD 9, 10, 1114 and 15 demographic and clinical characteristics in IBD patients including the medical therapy, phenotype and extent of disease.

\section{CARD9, CARD14 and CARD15 expressing cells in patients with UC and controls}

Histochemical analysis showed that colonic tissue from non-inflamed controls had a baseline expression of CARD9, CARD14 and CARD15 less than 10\% throughout the mucosa, submucosa, muscular and serosa layers (Figs. 2 and 3). Colonic tissue of UC patients had abundant inflammatory infiltrates, predominantly mononuclear cells, which extended from the serosa to mucosa, being more abundant in the epithelium, submucosa and serosa. CARD9 was expressed by inflammatory infiltrates (Fig. 2). The mucosa, submucosa and muscular from UC patients showed a statistically significant increase in CARD9 $^{+}$cell percentage versus non-inflamed tissue control group. However, CARD9 levels in muscular and serosa were lower in active UC compared with active CD (Fig. 4a).

CARD14 was expressed by parenchymal and endothelial cells, (Fig. 2). UC patients had significantly higher levels of CARD14 ${ }^{+}$cells compared to non-inflamed and CD control groups (Fig. 4b).

CARD15 was expressed in inflammatory infiltrates and parenchymal cells (Fig. 3). CD patients had higher levels of CARD15-expressing cells throughout intestinal tissue layers compared to UC and non-inflamed control group. Nonetheless, CARD14 had significantly higher expression in tissue from UC patients versus non-inflamed control group (Fig. 4c).

\section{Discussion}

CARDs family is composed by 15 molecules that are involved in innate host defense against gastrointestinal pathogens and in the regulation of inflammatory responses, suggesting that further insights into their physiological functions may yield new pharmacological strategies for treating intestinal inflammatory conditions [30]. 

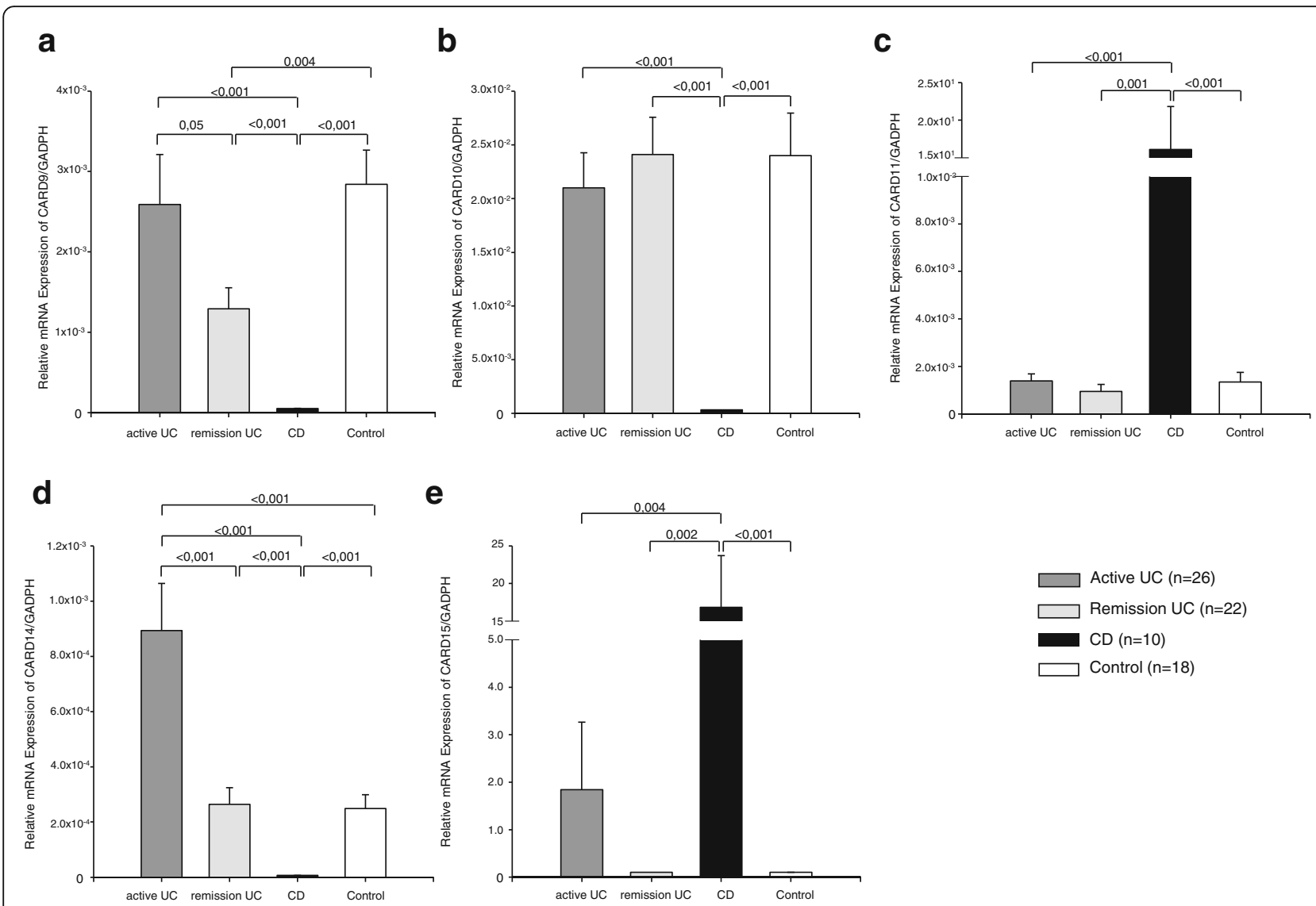

Fig. 1 CARDs Gene Expression in Colonic Tissue of Ulcerative Colitis Patients. a CARD9; b CARD10; c CARD11; d CARD14; and e CARD15 relative gene expression quantified by RT-PCR. Bars show mean \pm standard error of the mean of transcript levels in colonic mucosa from ulcerative colitis (UC) patients, active Crohn's disease (CD) patients, and non-inflamed controls with GAPDH as housekeeping gene determined by 2- $\triangle \triangle C \mathrm{Ct}$. A nonparametric Kruskall Wallis test was used for analyze differences between groups

The great interest to study the CARD family emerged from the impact that CARD15 has in the CD pathophysiology, regarding its implication in avoiding bacterial mucosal inflammation [7]. No previous studies have been evaluated in UC patients.

The findings of the present study showed that there is a differential gene and protein expression of some CARD family members due to the up-regulated expression of CARD9, CARD14 and CARD15, contrasting with the lack of significant expression in CARD 10 and 11 members in patients with UC.

Our findings suggest that CARD14 might be involved in the pathophysiology of UC, suggesting that CARD14 might play an important role concerning intestinal inflammation. Its relevance had previously been focused in patients with psoriasis, for instance, a Single Nucleotide Polymorphism (SNP) of this gene, named PSORS2 has been considered one of the major genetic risk factors for psoriasis. It has been proposed that CARD14 mutations lead to enhanced NF-kB activation and up-regulation of a subset of psoriasis-associated genes in keratinocytes, which up-regulates an acute inflammatory response throughout excessive activation of NF-kB responsive genes and initiating the recruitment of the inflammatory infiltrate where CARD14 seems to be a regulator of skin inflammation [31]. Similar findings have been made regarding generalized pustular psoriasis [32] and pitiriasis rubra pilaris [33].

Our results are relevant regarding the study of CARD14 as part of the large list of molecules implicated in the puzzling study of IBD etiology, besides suggesting the importance of studying other members of the CARD family. Therefore, this is a fertile ground to other studies regarding the further events that this study was not possible to address.

For instance, in the context of skin immunology, CARD14 protein expression has been found to be reduced in the basal layer, and more diffusely up regulated in the suprabasal layers of the epidermis, unlike the normal CARD14 expression localized mainly in the basal and suprabasal layers of healthy skin epidermis [31]. 


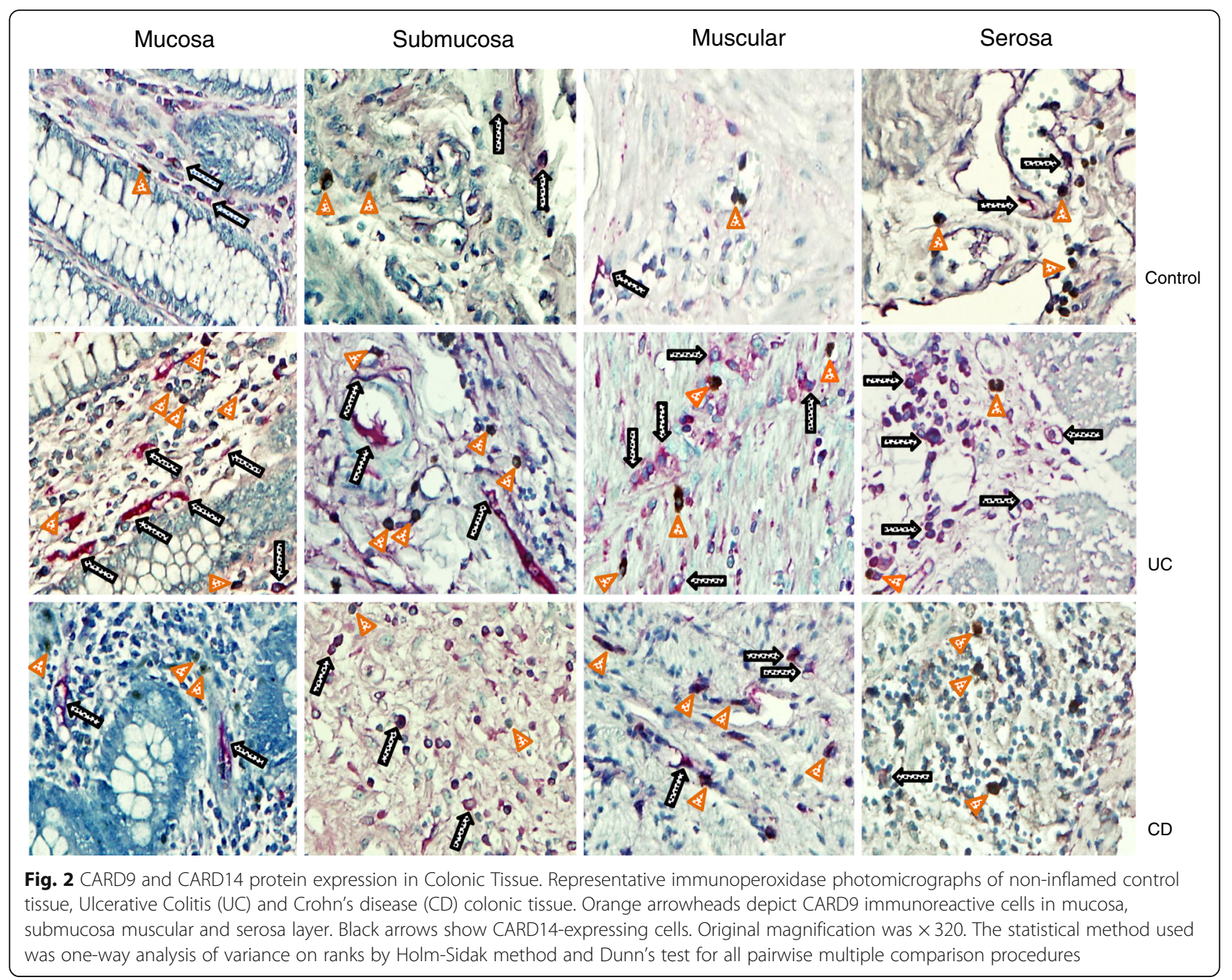

On the other hand, CARD9 is an important adaptor of innate immune signaling pathways and has not been explored in UC patients. CARD9 is predominantly expressed in immune cells such as: myeloid dendritic cells, macrophages, $\mathrm{T}$ lymphocytes and B lymphocytes. Previously, Bertin J et al., showed that CARD9 expression in the small intestine and colon was low under normal conditions, but it is probably that increases during mucosal inflammation due to an influx of myeloid cells [17]. It has been demonstrated that CARD9 promotes recovery from colitis through activation of the IL-22 pathway. Moreover, $\operatorname{Card~}^{-/-}$mice has an altered microbiota with increased load of gut-resident fungi, and reduced IL-22 production, and the transfer of microbiota from knockout mice to wild-type germ-free mice increases their susceptibility to colitis. In $\mathrm{Card}^{-/-}$administration of Lactobacillus murinos, L. reuteri and L. taiwanensis strains attenuates intestinal inflammation through catabolites generated by metabolism of tryptophan. These metabolites act as ligands for aryl hydrocarbon receptor
(AHR) that can modulate IL-22 production. Interestingly, reduced AHR ligands production was also observed in patients with IBD, mainly in those with CARD9 risk alleles associated with IBD [34-36]. We found a protein overexpression of CARD9 in inflamed colonic tissue of UC groups compared to controls without inflammation. These results can be explained due to CARD9 is required for signaling from TLRs in dendritic cells and Triggering Receptor Expressed on Myeloid Cells (TREM) family of receptors in myeloid cells, since activation of nuclear factor- $\mathrm{kB}$ and/ or Mitogen-Activated Protein Kinases (MAPK), and induction of the proinflammatory cytokines TNF and IL-6. Probably, the increase of CARD9 observed in our patients could be a compensatory mechanism of inflammation due to dysbiosis. However, we cannot rule out the possible lack of functionality or poor function of the protein.

In genetic studies from other populations, the presence of certain genetic variants of CARD9 has shown to imply an increased risk of UC, and the haplotype rs2078178- 


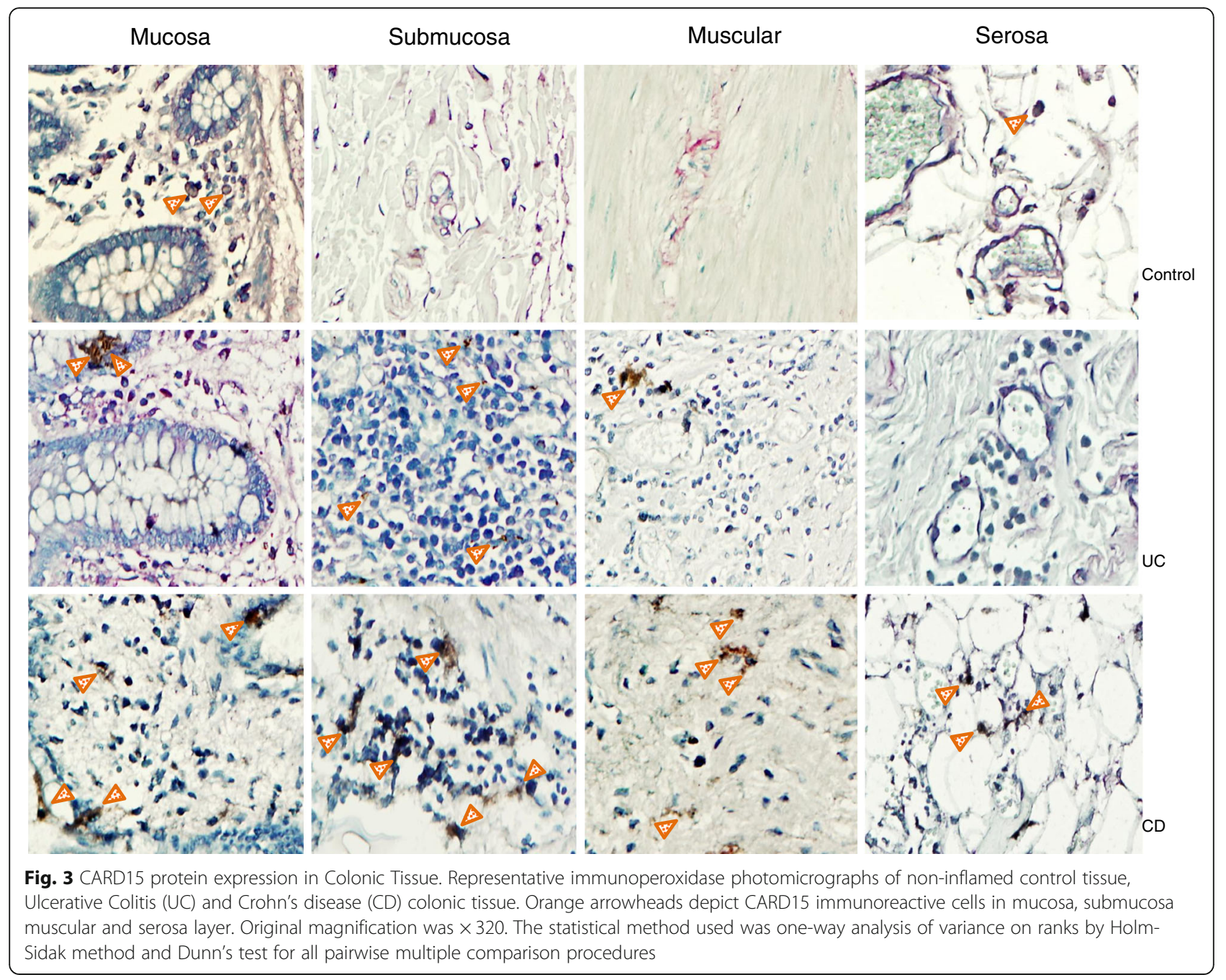

rs16910631 was found to be associated with refractory UC $[11,13]$. Zhernakova A et al., observed that the haplotype including the rs2287037*Grs1035130*G-rs2241116*C and rs6706002*A alleles occurred more frequently in IBD cases $(26.1 \%)$ than in controls $(21.4 \%)(P=0.006)[11,13]$.

In the same vein, CARD10 had not been explored in IBD patients. Our results showed that there is no significantly different gene expression of CARD10 in patients with active and remission UC compared to the non-inflamed control group.

Regarding the CARD11 gene expression no significant difference was found between UC patients and normal controls. The role of CARD11 mutations has been demonstrated in other types of diseases such as diffuse large B cell lymphoma [37], rheumatoid arthritis [38] and severe combined immunodeficiency [39]. In contrast, no previous studies have been performed in IBD patients.

We propose that further studies should be considered with a larger number of patients in order to find a statistically significant difference regarding CARD9 and CARD11 gene expression. This study entails the potential opportunity of finding one more possible explanation for the intense inflammation that characterizes IBD, waiting to be confirmed or rejected. The clinical relevance of these findings lies in the better understanding of UC pathophysiology.

Nevertheless, it has been suggested that not only the importance of the coiled-coil domains of CARD14, but also the ones of its related family members, such as CARD11, are important in regulating inflammation [40]. For this reason, attention needs to be further focused on the whole family role in intestinal mucosa immunity and the interaction between its members.

Although no risk alleles of NOD2/CARD15 have been associated in patients with UC, the NOD2/CARD15 gene expression was significantly higher in our cohort of patients with active UC compared to normal controls. No significant associations were found in the CARD15 gene expression regarding to clinical characteristics of UC. In this sense, Csillag et al., [41] previously demonstrated 


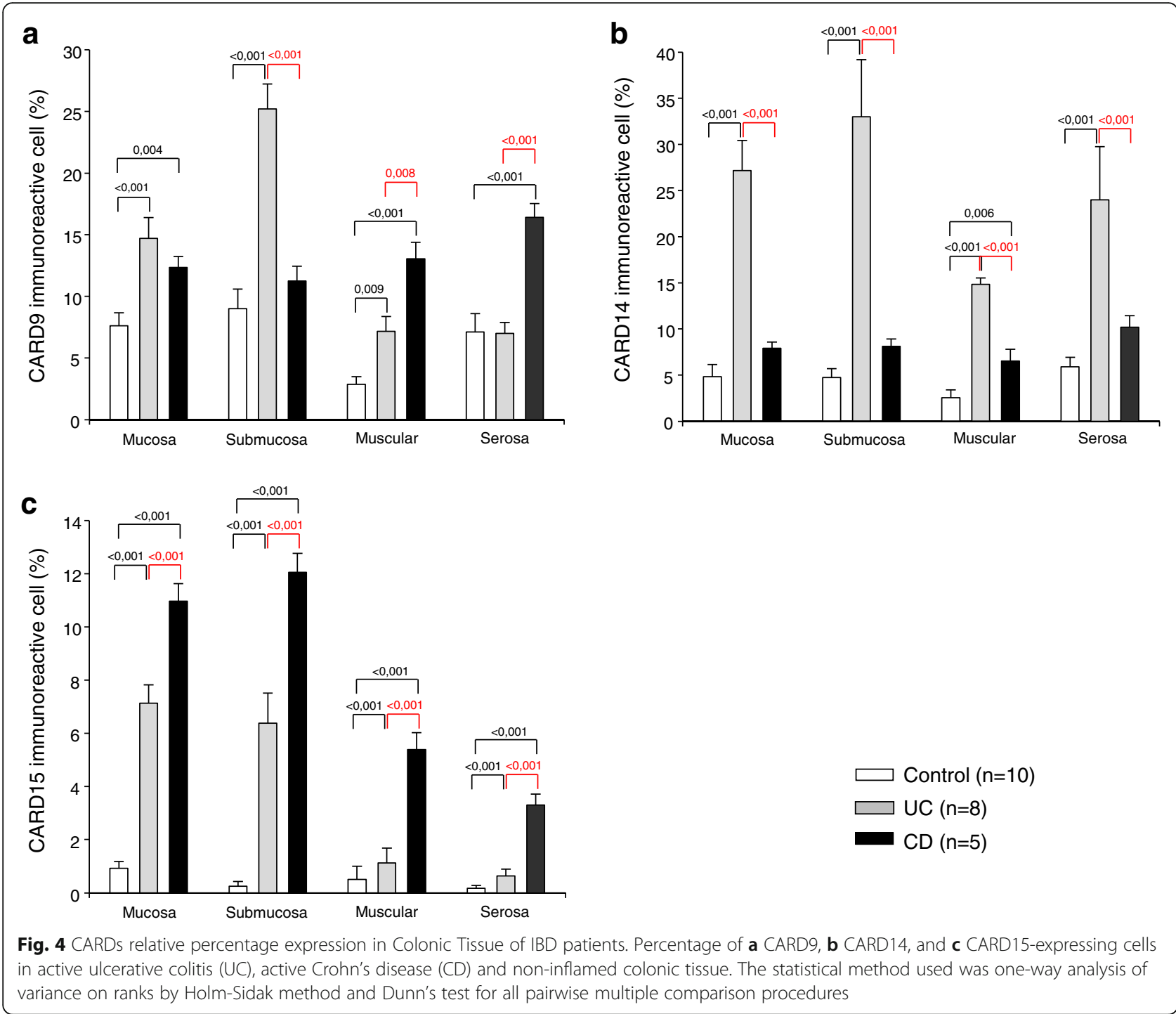

that gene expression profiling of mucosal biopsies from the descending colon of patients with $\mathrm{CD}$ could not be correlated with CARD15 status or with familial disposition for IBD. The over expression of CARD15 in CD immune cells was associated with expression of TNF and other pro-inflammatory cytokines, through NF-kB pathway [5].

Rosentiel P, et al. [42] demonstrated that TNF and IFN- $\gamma$ up-regulate the expression of CARD15 gene in human intestinal epithelial cells and subsequently increased their LPS susceptibility, proposing that CARD15 could be part of the complex pathophysiology of barrier disruption, as it is observed in IBD. These results are of interest because they suggest an up-regulation of CARD15 gene expression in inflammatory conditions.

The findings related to gene and protein CARDs expression are based on the increased cellular infiltrates, activation of the cells and treatment, besides the mRNA presence not always is related to protein expression (correlation between the RNA and protein profile is $\sim 33$ and 40\%). It depends on half-life of different proteins (minutes to days) and/or posttranscriptional modification, RNA transport mechanisms, mRNA degradation (2-7 h), complex gene regulatory mechanisms, RNA processing, alternative splicing, RNA stability, and so forth [43].

Besides, samples used to determine mRNA expression are only from colonic mucosa, due to the fact that tissue was obtained by colonoscopy. Nonetheless for immunohistochemistry surgical specimens were employed.

This study has the strength of being the first depiction about the role of the CARD family in UC. This is the first time that other members of the family were studied and also the differential expression of CARD14 and CARD15 between UC and non-inflamed controls.

The role of CARD9 and CARD14 in the immunobiology of IBD is important in order to carry out studies in animal models by eliminating these receptors in specific cell 
lineages such as intestinal epithelial cells or cells from innate immunity.

The novel findings of the present study about gene expression of CARD9 and CARD14 can differently distinguish active and remission UC suggesting that blocking these receptors with an antagonist might be used as new therapeutic target in UC patients.

CARD14 gene expression was increased in patients with active UC, and its low gene expression was associated with a benign clinical course characterized by long-term remission, suggesting that an up-regulation is a defense mechanism in the colonic epithelia in response to decreased bacterial invasion and inflammatory activity.

\section{Conclusion}

The CARD family might be involved in UC pathophysiology, due to the fact that CARD9, 14 and 15 gene expression was increased in patients with active UC.

The down-regulation of CARD14 was associated with a benign clinical course of UC characterized by long-term remission. Our results shed further light regarding the identification of CARDs in the pathophysiology of IBD.

\section{Abbreviations \\ CARD: Caspase Recruitment Domain; CD: Cronh's Disease; IBD: Inflammatory bowel disease; RT-PCR: Real Time Polymerase Chain Reaction; UC: Ulcerative Colitis \\ Funding \\ All resources were provided by funds of the Inflammatory Bowel Disease Clinic at the department of Gastroenterology, Instituto Nacional de Ciencias Médicas y Nutrición.}

\section{Availability of data and materials}

Availability of data supporting our findings can be provided if the paper is accepted for publication.

\begin{abstract}
Authors' contributions
JKYF designed and provided the research idea, directed, reassessed both clinical and histological diagnostic, data discussion analysis, prepare and coordinate the manuscript editing as well as provided the financial resources for performing the study. GFC participate during the sample processing, performed RT-qPCR analysis for CARDs transcript level quantification, Immunohistochemistry, data discussion analysis and prepared the manuscript. JFC participated Immunohistochemistry, data analysis and in critical reviewing and data discussion and analysis, critical reviewing, bibliographic analysis and the preparation of the manuscript. ASA performed RT-qPCR analysis transcript level quantification, clinical data collection and bibliographic analysis of the manuscript. RBZ participate in the colonic sample collection and endoscopic evaluation. BMB participate in the histological analysis and preparation of tissue for immunohistochemistry. MALV performed RT-qPCR analysis transcript level quantification. All authors read and approved the final manuscript.
\end{abstract}

\section{Ethics approval and consent to participate}

This study was performed according to the principles expressed in the Declaration of Helsinki. The study was approved by the Ethics and Research Committee from the Instituto Nacional de Ciencias Médicas y Nutrición with reference number 1485, and a written informed consent was obtained from all subjects.

\section{Consent for publication}

Not applicable.

\section{Competing interests}

The authors declare that they have no competing interests.

\section{Publisher's Note}

Springer Nature remains neutral with regard to jurisdictional claims in published maps and institutional affiliations.

\section{Author details}

${ }^{1}$ Department of Gastroenterology, Inflammatory Bowel Disease Clinic, Instituto Nacional de Ciencias Médicas y Nutrición Salvador Zubirán, Vasco de Quiroga 15, Colonia Sección XVI, Tlalpan, CP, 14000 Mexico City, Mexico. ${ }^{2}$ Department of Immunology and Rheumatology, Instituto Nacional de Ciencias Médicas y Nutrición Salvador Zubirán, Mexico City, Mexico. ${ }^{3}$ Department of Endoscopy, Instituto Nacional de Ciencias Médicas y Nutrición Salvador Zubirán, Mexico City, Mexico. ${ }^{4}$ Department of Pathology, National Institute of Medical Science and Nutrition "Salvador Zubirán", Mexico City, Mexico. ${ }^{5}$ Facultad de Medicina, Universidad Nacional Autónoma de México, Av. Ciudad Universitaria 3000, C.P. Coyoacán, 04360 México City, Mexico.

Received: 9 January 2018 Accepted: 18 June 2018

Published online: 11 July 2018

\section{References}

1. Molodecky NA, Soon IS, Rabi DM, et al. Increasing incidence and prevalence of the inflammatory bowel diseases with time, based on systematic review. Gastroenterology. 2012;142(1):46-54.

2. Sartor RB. Mechanisms of disease: pathogenesis of Crohn's disease and ulcerative colitis. Nat Clin Pract Gastroenterol Hepatol. 2006;3(7):390-407.

3. Van Limbergen J, Radford-Smith G, Satsangi J. Advances in IBD genetics. Nat Rev Gastroenterol Hepatol. 2014;11(6):372-85.

4. Girardin SE, Boneca G, Viala J, et al. Nod2 is a general sensor of peptidoglycan through muramyl dipeptide (MDP) detection. J Biol Chem. 2003;278(11):8869-72.

5. Yamamoto-Furusho JK, Barnich N, Hisamatsu T, Podolsky DK. MDP-NOD2 stimulation induces HNP-1 secretion, which contributes to NOD2 antibacterial function. Inflamm Bowel Dis. 2010;16(5):736-42.

6. Ogura $Y$, Inohara N, Benito A, et al. Nod2, a Nod1/Apaf-1 family member that is restricted to monocytes and activates NF-kappaB. J Biol Chem. 2001; 276(7):4812-8

7. Wehkamp J, Harder J, Weichenthal M, et al. NOD2 (CARD15) mutations in Crohn's disease are associated with diminished mucosal a-defensin expression. Gut. 2004;53(11):1658-64

8. Couturier-Maillard A, Secher T, Rehman A, et al. NOD2-mediated dysbiosis predisposes mice to transmissible colitis and colorectal cancer. J Clin Invest. 2013;123(2):700-11.

9. Wu W, Hsu YM, Bi L, Songyang Z, Lin X. CARD9 facilitates microbe-elicited production of reactive oxygen species by regulating the LyGDI- Rac1 complex. Nat Immunol. 2009;10(11):1208-14.

10. Hsu YM, Zhang Y, You Y, et al. The adaptor protein CARD9 is required for innate immune responses to intracellular pathogens. Nat Immunol. 2007; 8(2):198-205.

11. Iliev ID, Funari VA, Taylor KD, et al. Interactions between commensal fungi and the c-type lectin receptor dectin-1 influence colitis. Science. 2012; 336(6086):1314-7

12. Ruland J. CARD9 signaling in the innate immune response. Ann N Y Acad Sci. 2008;1143:35-44.

13. Zhernakova A, Festen EM, Franke L, et al. Genetic analysis of innate immunity in Crohn's disease and ulcerative colitis identifies two susceptibility loci harboring CARD9 and IL18RAP. Am J Hum Genet. 2008; 82(5):1202-10

14. Lucas PC, McAllister-Lucas LM, Nunez G. NF-kB signaling in lymphocytes: a new cast of characters. J Cell Sci. 2004;117(Pt 1):31-9.

15. Dimitratos SD, Woods DF, Stathakis DG, Bryant PJ. Signaling pathways are focused at specialized regions of the plasma membrane by scaffolding proteins of the MAGUK family. BioEssays. 1999;21(11):912-21.

16. Fanning AS, Anderson JM. Protein modules as organizers of membrane structure. Curr Opin Cell Biol. 1999;11(4):432-9.

17. Bertin J, Wang L, Guo Y, et al. CARD11 and CARD14 are novel caspase recruitment domain (CARD)/membrane-associated guanylate kinase 
(MAGUK) family members that interact with BCL10 and activate NF-kappa B. J Biol Chem. 2001;276(15):11877-82.

18. Gaide $\mathrm{O}$, Favier B, Legler DF, et al. CARMA1 is a critical lipid raft-associated regulator of TCR-induced NF-kappa B activation. Nat Immunol. 2002;3(9): 836-43.

19. McAllister-Lucas $L M$, Inohara $N$, Lucas $P C$, et al. Bimp1, a MAGUK family member linking protein kinase $\mathrm{C}$ activation to BCl10-mediated NF-kappaB induction. J Biol Chem. 2001;276(33):30589-97.

20. Wang L, Guo Y, Huang WJ, et al. CARD10 is a novel caspase recruitment domain/membrane-associated guanylate kinase family member that interacts with BCL10 and activates NF- KB. J Biol Chem. 2001;276(24):21405-9.

21. Borthakur A, Bhattacharyya S, Alrefai WA, et al. Platelet-activating factorinduced NF-kappaB activation and IL-8 production in intestinal epithelial cells are Bcl10-dependent. Inflamm Bowel Dis. 2010;16(4):593-603.

22. Scudiero I, Vito P. Stilo R. The three CARMA sisters: so different, so similar: a portrait of the three CARMA proteins and their involvement in human disorders. J Cell Physiol. 2014;229(8):990-7.

23. Blonska M, Lin X. NF-kB signaling pathways regulated by CARMA family of scaffold proteins. Cell Res. 2011;21(1):55-70.

24. Scudiero I, Zotti T, Ferravante A, Vessichelli M, Vito P, Stilo R. Alternative splicing of CARMA2/CARD14 transcripts generates protein variants with differential effect on NF- kB activation and endoplasmic reticulum stressinduced cell death. J Cell Physiol. 2011;226(12):3121-31.

25. Fuchs-Telem D, Sarig O, van Steensel MA, et al. Familial pityriasis rubra pilaris is caused by mutations in CARD14. Am J Hum Genet. 2012;91(1): 163-70.

26. Riley SA, Mani V, Goodman MJ, Herd ME, Dutt S, Turnberg LA. Comparison of delayed release 5 aminosalicylic acid (mesalazine) and sulphasalazine in the treatment of mild to moderate ulcerative colitis relapse. Gut. 1988;29(5): 669-74.

27. Schroeder KW, Tremaine WJ, Ilstrup DM. Coated oral 5-aminosalicylic acid therapy for mildly to moderately active ulcerative colitis. A randomized study. N Engl J Med. 1987;317(26):1625-9.

28. Henriksen M, Jahnsen J, Lygren I, et al. Ulcerative colitis and clinical course: results of a 5-year population-based follow-up study (the IBSEN study). Inflamm Bowel Dis. 2006;12(7):543-50.

29. Harvey RF, Bradshaw JM. A simple index of Crohn's-disease activity. Lancet. 1980;1(8167):514.

30. Hruz P, Eckmann L. Caspase recruitment domain-containing sensors and adaptors in intestinal innate immunity. Curr Opin Gastroenterol. 2008;24(2): 108-14.

31. Jordan $C T$, Cao L, Roberson ED, et al. PSORS2 is due to mutations in CARD14. Am J Hum Genet. 2012;90(5):784-95.

32. Sugiura K. The genetic background of generalized pustular psoriasis: IL36RN mutations and CARD14 gain-of-function variants. J Dermatol Sci. 2014;74(3): 187-92.

33. Eytan O, Sarig O, Sprecher E, van Steelsen MA. Clinical response to ustekinumab in familial pityriasis rubra pilaris caused by a novel mutation in CARD14. Br J Dermatol. 2014;171 (2):420-2.

34. Etienne-Mesmin L, Chassaing B, Gewirtz AT. Tryptophan: a gut microbiotaderived metabolites regulating inflammation. World J Gastrointest Pharmacol Ther. 2017;8(1):7-9.

35. Lamas B, Richard ML, Leducq V, et al. CARD9 impacts colitis by altering gut microbiota metabolism of tryptophan into aryl hydrocarbon receptor ligands. Nat Med. 2016;22(6):598-605.

36. Imhann F, Vich Vila VA, Bonder MJ, et al. Interplay of host genetics and gut microbiota underlying the onset and clinical presentation of inflammatory bowel disease. Gut. 2016;65:740-8

37. Carbone A, Gloghini A, Kwong YL, Younes A. Diffuse large B cell lymphoma: using pathologic and molecular biomarkers to define subgroups for novel therapy. Ann Hematol. 2014;93(8):1263-77.

38. Wang $H$, Zhao J, Zhang $H$, Huang $Y$, Wang $S$, Tu Q, Yang N. CARD11 blockade suppresses murine collagen-induced arthritis via inhibiting CARD11/Bcl10 assembly and T helper type 17 response. Clin Exp Immunol. 2014;176(2):238-45.

39. Stepensky P, Keller B, Buchta M, et al. Deficiency of caspase recruitment domain family, member 11 (CARD11), causes profound combined immunodeficiency in human subjects. J Allergy Clin Immunol. 2013;131(2):477-85.

40. Jun JE, Wilson LE, Vinuesa CG, et al. Identifying the MAGUK protein Carma-1 as a central regulator of humoral immune responses and atopy by genome-wide mouse mutagenesis. Immunity. 2003;18(6):751-62.
41. Csillag C, Nielsen OH, Borup R, Bjerrum JT, Cilius Nielsen F. CARD15 status and familial predisposition for Crohn's disease and colonic gene expression. Dig Dis Sci. 2007;52(8):1783-9.

42. Rosentiel P, Fantinni M, Bräutigman K, et al. TNF-alpha and INF-gamma regulate the expression of NOD2 (CARD15) gene in human intestinal epithelial cells. Gastroenterology. 2003;124(4):1001-9.

43. Yamamoto-Furusho JK. Peroxisome proliferator-activated receptors family is involved in the response to treatment and mild clinical course in patients with ulcerative colitis. Dis Markers. 2014;2014:932530.

\section{Ready to submit your research? Choose BMC and benefit from:}

- fast, convenient online submission

- thorough peer review by experienced researchers in your field

- rapid publication on acceptance

- support for research data, including large and complex data types

- gold Open Access which fosters wider collaboration and increased citations

- maximum visibility for your research: over $100 \mathrm{M}$ website views per year

At BMC, research is always in progress.

Learn more biomedcentral.com/submissions 